\title{
Penerapan Penjejak Titik Daya Maksimum Pada Plts Skala Kecil di SMK Negeri 1 Pringgabaya
}

\author{
Abdul Natsir, Supriyatna, Ida Ayu Sri Adnyani, Ni Made Seniari, Sabar Nababan, Rosmaliati \\ Teknik Elektro, Universitas Mataram, Mataram, Indonesia.
}

Alamat korespondensi : natsir.amin@unram.ac.id

\begin{abstract}
ABTRAK
Dalam kebijakan energi nasional, pemerintah terus berkomitmen untuk melakukan pengembangan dan meningkatkan pemanfaatan pembangkit energi terbarukan hingga 23 persen pada tahun 2025. Saat ini, potensi energi terbarukan di Indonesia belum dimanfaatkan dengan optimal. Hal ini terlihat dari potensi energi terbarukan Indonesia mencapai kira-kira $400 \mathrm{GW}$, yang terealisasi pemanfaatannya hanya $32 \mathrm{GW}$ atau sekitar $8 \%$ di akhir tahun 2019. Kontroler pengisi surya atau solar charge controller (SCC) merupakan komponen elektronik daya yang digunakan di PLTS untuk mengatur pengisian baterai dengan menggunakan modul fotovoltaik (PV) agar menjadi lebih optimal. Penjejak titik daya maksimum atau Maximum Power Point Tracking (MPPT) adalah sebuah algoritma atau teknik yang digunakan oleh kontroler pengisi untuk melacak dan mendapatkan nilai daya maksimum dari modul PV dalam kondisi tertentu. Kegiatan pengabdian kepada masyarakat ini dilakukan untuk merancang dan menerapkan MPPT pada kontroler pengisi PLTS yang berlokasi di SMKN 1 Pringgabaya. Hasil pengujian dan pengukuran data menunjukkan bahwa daya keluaran yang dihasilkan modul PV yang menggunakan MPPT relatif lebih besar jika dibandingkan dengan daya yang dihasilkan modul PV tanpa menggunakan MPPT. Hasil pengukuran tertinggi ditunjukkan pada kondisi intensitas radiasi surya sebesar 704,4 Watt/m2, modul PV dengan menggunakan MPPT dan tanpa MPPT yang masing-masing menghasilkan daya sebesar 52,60 Wp dan 38,04 Wp.
\end{abstract}

Kata kunci: Pembangkit listrik tenaga surya, kontroler pengisi surya, konverter buck, penjejak titik daya maksimum.

\section{PENDAHULUAN}

Seiring dengan adanya program 35.000 MW untuk Indonesia dan pelaksanaan kedaulatan energi sesuai dalam Peraturan Pemerintah No. 79 tahun 2014 tentang Kebijakan Energi Nasional, pemerintah berkomitmen untuk meningkatkan pengembangan dan penggunaan pembangkit energi terbarukan hingga 23 persen pada tahun 2025. Hal ini sejalan dengan tujuan Sustainable Development Goals (SDGs) ke-7, yaitu menjamin akses terhadap energi yang terjangkau, handal, berkelanjutan, dan modern bagi semua pada tahun 2030 .

Saat ini, potensi energi terbarukan yang tersebar di Indonesia belum dimanfaatkan dengan optimal. Hal ini terlihat dari potensi energi terbarukan yang dimiliki Indonesia yang mencapai $400 \mathrm{GW}$, yang terealisasi pemanfaatannya hanya $32 \mathrm{GW}$ atau sekitar $8 \%$ di akhir tahun 2019. Juga rasio elektrifikasi Indonesia yang telah mencapai sekitar 98,89 persen di tahun 2019, sebagian besar daerah yang belum mendapatkan akses listrik adalah daerah pedesaan yang terpencil dan terisolir. Provinsi NTB merupakan salah satu lokasi yang membutuhkan pengembangan pembangkit energi terbarukan untuk memperluas jangkauan listrik ke pedesaan dan mengurangi resiko pemadaman listrik secara bergilir, dengan cara yang lebih murah serta menghasilkan emisi yang lebih rendah.

Wujud nyata dari pemanfaatan pembangkit energi terbarukan adalah banyaknya pembangunan pembangkit energi terbarukan off-grid di daerah-daerah terpencil yang belum mendapatkan akses energi listrik dari PLN, penerangan jalan umum (PJU) tenaga surya, dan hibah pembangkit energi terbarukan bagi sekolah menengah kejuruan (SMK) di provinsi NTB. 
Sasaran kegiatan pengabdian masyarakat adalah meningkatkan pengetahuan dan keterampilan siswa-siswi SMK terkait teknologi pembangkit energi terbarukan yang diinstal di sekolah sehingga peralatan-peralatan bermanfaat dan dapat digunakan untuk jangka waktu yang panjang. Tujuan yang ingin dicapai sebagai luaran kegiatan pengabdian kepada masyarakat adalah memaksimalkan daya listrik yang dihasilkan dari pembangkit energi terbarukan dengan tingkat ketergantungan terhadap cuaca sangat tinggi (intermittent) seperti PLTS dan PLTB skala kecil. Sehingga diperlukan sebuah alat yang disebut Charger Controller dengan metode Maximum Power Point Tracking (MPPT) atau Penjejak Titik Daya Maksimum.

Keberadaan pembangkit energi terbarukan di SMK tidak hanya dianggap sebagai suatu hibah atau pemberian saja, siswa dan guru harus melakukan inovasi dan kreatifitas untuk memanfaatkan secara optimal dan mengembangkan komponen-komponen pembangkit tersebut. Salah satu inovasi yang dapat dilakukan adalah memaksimalkan daya listrik yang dihasilkan oleh PLTS. Sehingga permasalahan yang muncul adalah bagaimana memaksimalkan daya listrik pada PLTS skala kecil dengan kondisi pembangkit yang sangat tergantung pada perubahan cuaca yaitu intensitas radiasi surya dan kecepatan angin yang selalu bervariaisi setiap saat.

\section{METODE KEGIATAN}

Kegiatan pengabdian kepada masyarakat ini dilaksanakan di SMK Negeri 1 Pringgabaya, kabupaten Lombok Timur provinsi Nusa Tenggara Barat. SMK ini memiliki PLTS skala kecil kapasitas $1 \mathrm{~kW}$. Peralatan-peralatan yang digunakan yaitu PLTS (modul surya), multimeter digital, baterai VRLA 12V, 70 Ah dan osciloscop digital. Sedangkan bahan atau komponen pendukung meliputi Arduino uno R3 ATmega 328, DC-DC buck converter, sensor tegangan, sensor arus ACS712 20A, resistor, dioda, LCD display (20 x 4) dan kabel konektor.

Metode yang digunakan pada kegiatan ini adalah perancangan dan penerapan penjejak titik daya maksimum pada PLTS skala kecil dengan metode Perturb and Observe $(P \& O)$ berbasis Arduino Uno (Wibawa, 2015). Daya maksimum yang didapatkan digunakan untuk mengisi baterai pada sistem off-grid. Sistem ini bekerja dengan cara menghubungkan modul surya dengan rangkaian $D C-D C$ Buck Converter, selanjutnya output dari $D C$-DC Buck Converter dihubungkan dengan beban (baterai). Output DC-DC Buck Converter dikontrol menggunakan Arduino Uno, dengan penerapan algoritma Perturb and Observe pada pemrograman IDE Arduino Uno berdasarkan nilai input dari sensor arus dan sensor tegangan yang dihubungkan pada sisi keluaran modul surya dan masukan menuju baterai.

Nilai yang dikeluarkan oleh Arduino Uno adalah berupa duty cycle yang bervariasi berdasarkan nilai intensitas radiasi matahari dan suhu modul surya untuk menjaga modul surya bekerja pada tegangan titik daya maksimumnya. Hasil yang didapatkan berupa tegangan, arus dan daya output pada sisi modul surya maupun DC-DC Buck Converter akan ditampilkan pada sebuah LCD (Mujahidin, 2018). Konfigurasi sistem MPPT ditunjukkan pada Gambar 1. 


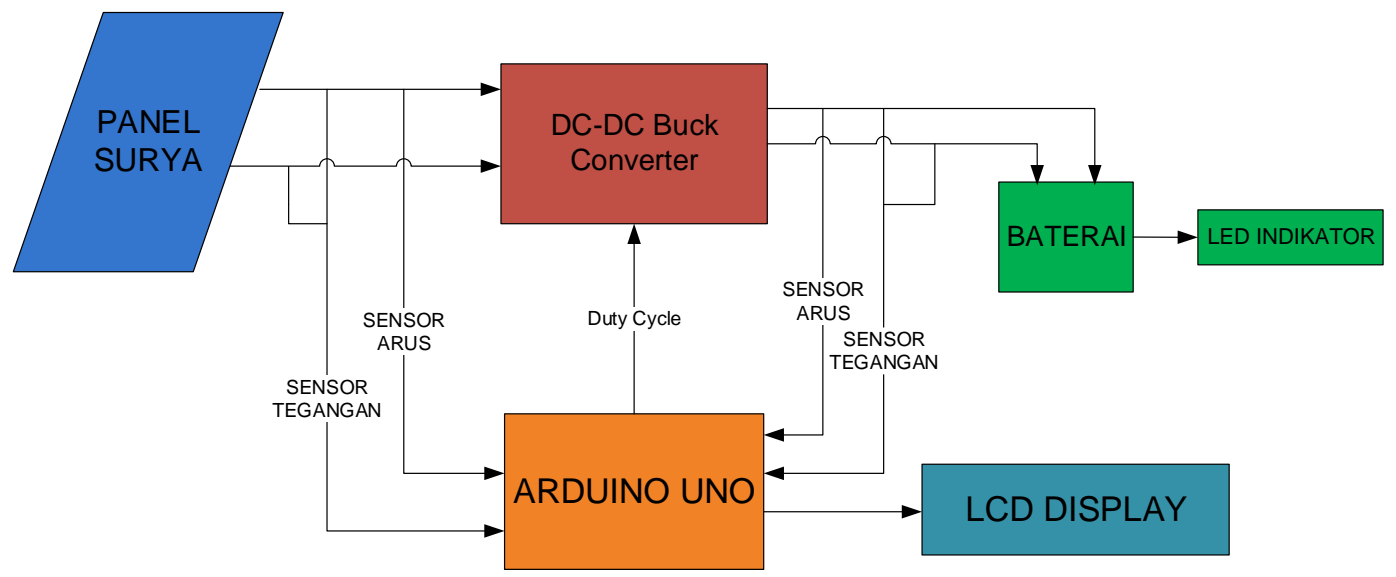

Gambar 1. Blok diagram perancangan solar charger controller dengan MPPT

\section{Prinsip Kerja Modul Surya}

Modul surya adalah komponen elektronika yang dapat mengubah energi surya menjadi energi listrik dalam bentuk arus searah (DC) yang disusun oleh semikonduktor tipe $\mathrm{n}$ dan tipe p yang membentuk junction $\mathrm{p}-\mathrm{n}$.

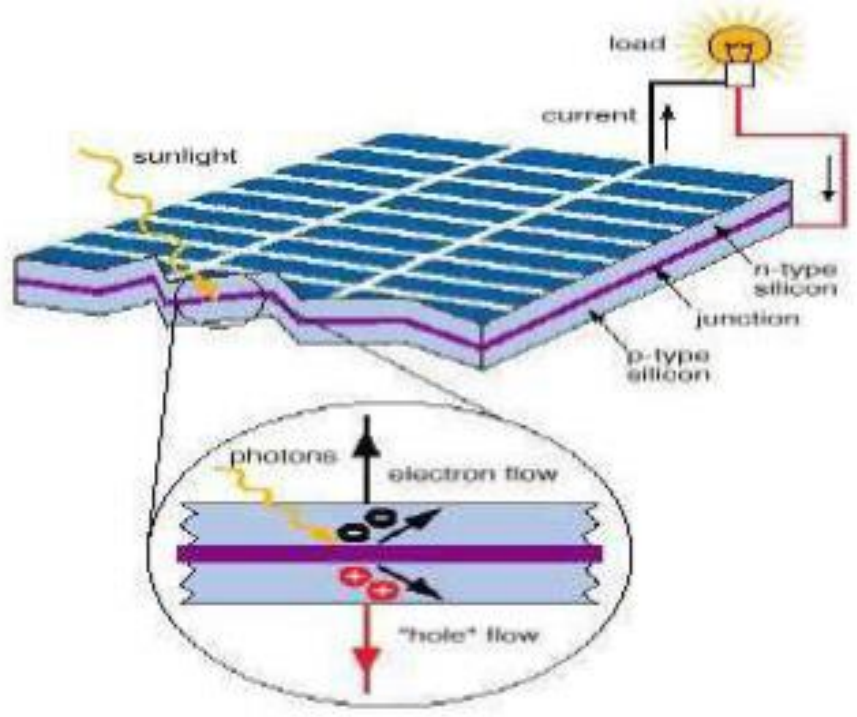

Gambar 2. Prinsip kerja modul surya (Ardana, 2019)

Secara garis besar prinsip kerja dari modul surya seperti gambar 2. Jika foton menumbuk atom silicon dari modul surya dan menghasilkan energi yang cukup untuk mendorong elektron valensi keluar dari orbitnya dan membentuk hole, maka akan timbul elektron-elektron bebas yang siap mengalir di ujung-ujung terminal modul surya. Jika beban seperti lampu dipasang diantara terminal negatif dan positif dari modul surya, maka elektronelektron akan mengalir sebagai arus listrik searah.

\section{Daya Maksimum}

Kurva karakteristik V-I seperti pada Gambar 3 memperlihatkan titik lengkung operasi dimana modul surya akan menghantarkan daya maksimum yang tersedia menuju beban. Daya titik maksimum yang dihasilkan modul surya pada saat diberi beban dihasilkan dengan cara mengalikan tegangan titik daya maksimum ( $\mathrm{V}_{\mathrm{MPP}}$ ) dan arus titik daya maksimum ( $\left.\mathrm{I}_{\mathrm{MPP}}\right)$. Titik ini dinamakan maximum power point $(M P P)$ atau daya maksimum dari modul surya, sesuai persamaan (Rekioua, 2012): 
dengan:

$$
P_{M P P}=V_{M P P} \times I_{M P P}
$$

$\mathrm{P}_{\mathrm{MPP}}=$ Daya maksimum $($ Watt $)$

$\mathrm{V}_{\mathrm{MPP}}=$ Tegangan maksimum $($ Volt $)$

$\mathrm{I}_{\mathrm{MPP}}=$ Arus maksimum (Ampere)

\section{Maximum Power Point Tracking (MPPT)}

Maximum Power Point Tracking (MPPT) atau Penjejak Titik Daya Maksimum adalah sebuah metode yang digunakan untuk melacak dimana titik operasi maksimum yang harus digunakan modul surya agar daya yang dihasilkan bernilai maksimal.

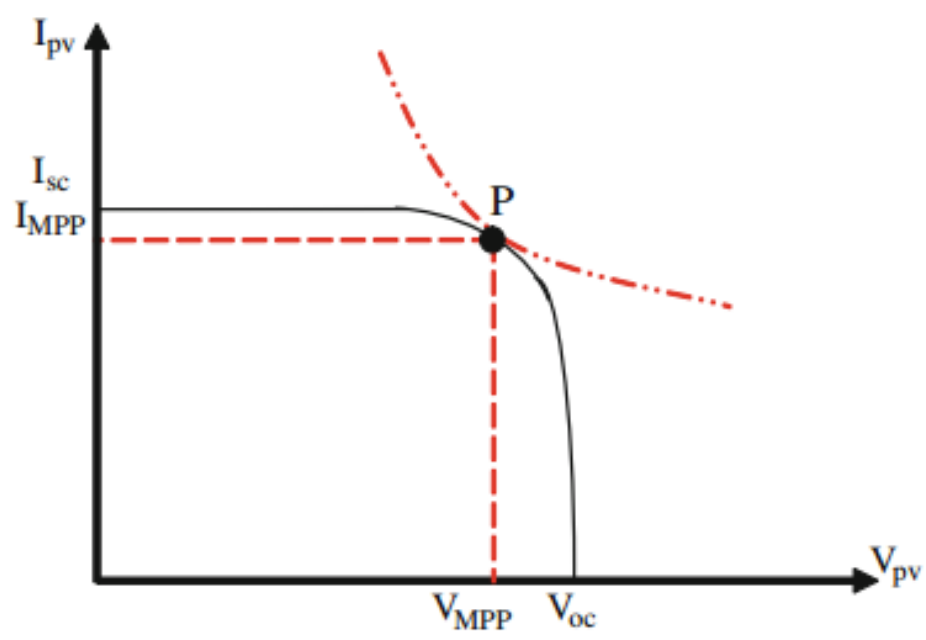

Gambar 3. Kurva karakteristik V-I pada titik daya maksimum (Rekioua, 2012).

Untuk mendapatkan titik operasi maksimum maka tegangan modul surya akan diregulasi meningkat ketika perbandingan antara daya dan tegangan bernilai positif kemudian tegangan akan diregulasi menurun ketika perbandingan antara daya dan tegangan bernilai negatif.

Untuk mengimplementasikan regulasi tegangan dalam metode MPPT maka modul surya perlu dihubungkan dengan sebuah pengendali konverter DC-DC baik berupa Buck Converter atau Boost Converter tergantung dari kondisi modul surya dan jenis beban yang digunakan.

\section{Perturb and Observe $(P \& O)$}

Metode Perturb and Observe $(P \& O)$ adalah salah satu metode yang banyak digunakan untuk melacak titik daya maksimum dari modul surya karena struktur implementasi algoritma yang sederhana dan hasil yang cukup akurat.

Metode ini bekerja dengan cara jika tegangan yang beroperasi pada modul surya diberikan pertubasi dengan arah tertentu dan daya keluaran modul surya meningkat mendekati titik daya maksimum, maka titik operasi pertubasi tegangan akan searah dengan pertambahan daya keluaran dari modul surya. Jika tegangan yang dipertubasi menghasilkan daya keluaran modul surya menurun dari daya keluaran sebelumnya, maka titik operasi pertubasi tegangan akan berlawanan arah daya keluaran sehingga nilai daya keluaran modul surya akan dijaga dan berosilasi pada titik daya maksimum tersebut. 


\section{HASIL DAN PEMBAHASAN}

Luaran yang diharapkan dari kegiatan pengabdian kepada masyarakat ini adalah sebuah rancang bangun prototip solar charger controller (SCC) dengan penjejak titik daya maksimum, seperti ditunjukkan pada Gambar 4. Penjejak titik daya maksimum ini dapat memaksimalkan daya listrik yang dihasilkan modul surya atau modul fotovoltaik.

Untuk menilai kinerja prototip solar charger controller dengan penjejak titik daya maksimum, maka harus dilakukan pengujian dan pengukuran data. Pengujian prototip ini dilakukan di laboratorium energi baru dan terbarukan menggunakan dua unit modul surya polikristal $65 \mathrm{Wp}$. Satu unit modul surya dihubungkan solar charger controller dengan MPPT dan satu unit modul surya lainnya tanpa MPPT. Pengambilan data pengukuran dilakukan selama 1 hari dari pukul 10.30 sampai dengan 15.00, seperti disajikan pada Tabel 1.

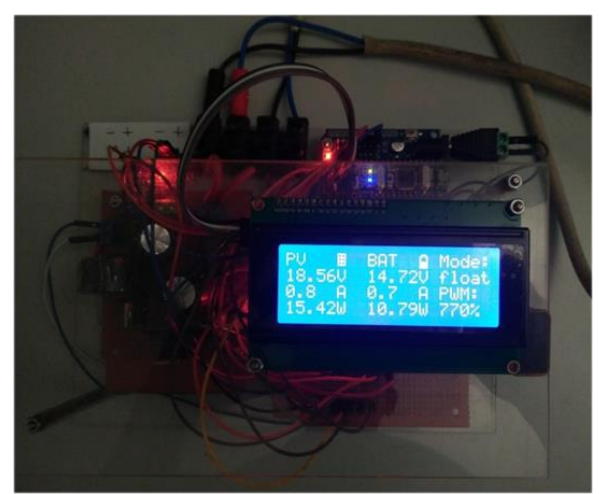

Gambar 4. Prototip solar charger controller dengan penjejak titik daya maksimum

Tabel 1. Data pengukuran dan perhitungan modul surya

\begin{tabular}{cccccccc}
\hline & \multirow{2}{*}{$\begin{array}{c}\text { Iradiasi } \\
\text { Jam }\end{array}$} & \multicolumn{3}{c}{$\begin{array}{c}\text { Modul surya dengan } \\
\text { MPPT }\end{array}$} & \multicolumn{3}{c}{$\begin{array}{c}\text { Modul surya tanpa } \\
\text { MPPT }\end{array}$} \\
\cline { 3 - 8 } & & $\mathbf{V}_{\mathbf{m p}}(\mathbf{V})$ & $\mathbf{I}_{\mathbf{m p}}(\mathbf{A})$ & $\mathbf{P}_{\mathbf{m p}}(\mathbf{W})$ & $\mathbf{V}_{\mathbf{m p}}(\mathbf{V})$ & $\mathbf{I}_{\mathbf{m p}}(\mathbf{A})$ & $\mathbf{P}_{\mathbf{m p}}(\mathbf{W})$ \\
\hline $10: 30$ & 504.4 & 15.56 & 2.70 & 42.01 & 15.38 & 2.20 & 33.84 \\
$10: 45$ & 540.6 & 15.15 & 2.90 & 43.94 & 15.17 & 2.20 & 33.37 \\
$11: 00$ & 464.4 & 15.46 & 2.50 & 38.65 & 15.47 & 2.00 & 30.94 \\
$11: 15$ & 571.9 & 15.24 & 3.10 & 47.24 & 15.96 & 2.00 & 31.92 \\
$11: 30$ & 639.4 & 15.35 & 3.30 & 50.66 & 15.52 & 2.40 & 37.25 \\
$11: 45$ & 673.1 & 15.11 & 3.30 & 49.86 & 15.24 & 2.30 & 35.05 \\
$12: 00$ & 671.9 & 15.58 & 3.20 & 49.86 & 15.63 & 2.40 & 37.51 \\
$12: 15$ & 704.4 & 15.47 & 3.40 & 52.60 & 15.85 & 2.40 & 38.04 \\
$12: 30$ & 663.1 & 15.51 & 3.20 & 49.63 & 15.89 & 2.30 & 36.55 \\
$12: 45$ & 636.9 & 15.13 & 3.10 & 46.90 & 15.63 & 2.30 & 35.95 \\
$13: 00$ & 494.4 & 15.64 & 2.60 & 40.66 & 15.02 & 2.20 & 33.04 \\
$13: 15$ & 451.9 & 14.81 & 2.20 & 32.58 & 16.28 & 1.40 & 22.79 \\
$13: 30$ & 400.6 & 15.88 & 1.70 & 27.00 & 14.54 & 1.60 & 23.26 \\
$13: 45$ & 479.4 & 14.79 & 2.20 & 32.54 & 15.46 & 1.80 & 27.83 \\
$14: 00$ & 396.9 & 16.44 & 1.60 & 26.30 & 15.09 & 1.50 & 22.64 \\
$14: 15$ & 463.1 & 15.42 & 2.50 & 38.55 & 15.48 & 2.00 & 30.96 \\
$14: 30$ & 586.9 & 15.09 & 2.60 & 39.23 & 14.37 & 2.30 & 33.05 \\
$14: 45$ & 569.4 & 15.46 & 2.40 & 37.10 & 15.49 & 1.90 & 29.43 \\
$15: 00$ & 535.6 & 15.50 & 2.20 & 34.10 & 15.96 & 1.80 & 28.73 \\
\hline
\end{tabular}




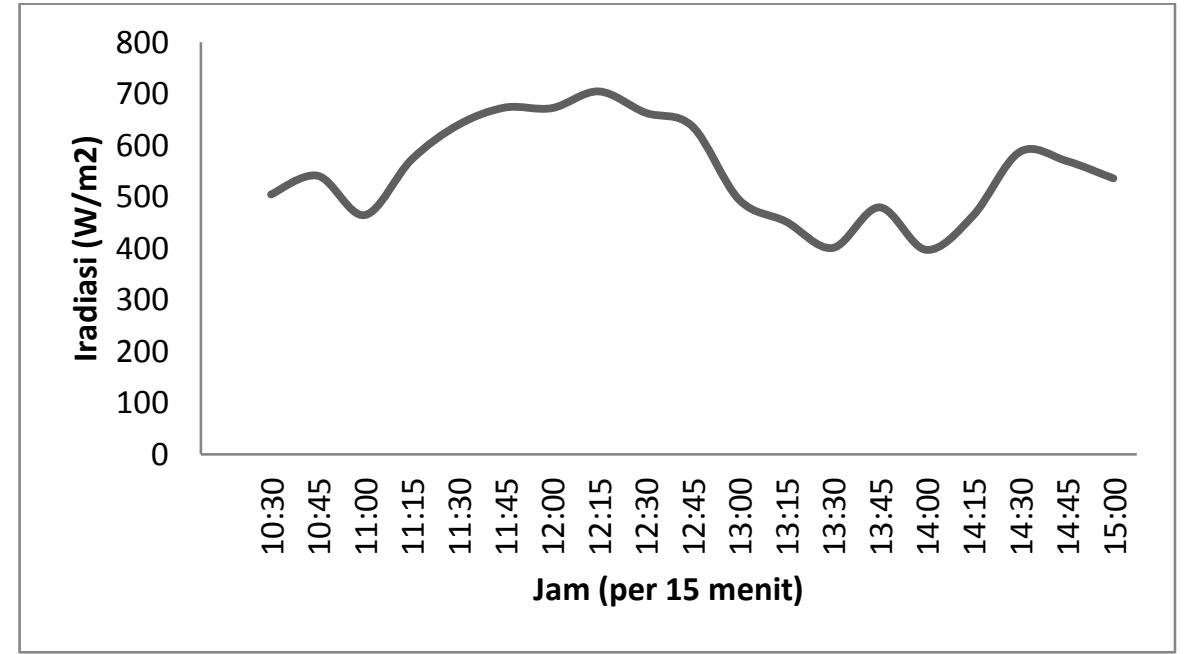

Gambar 5. Grafik Iradiasi saat melakukan pengukuran

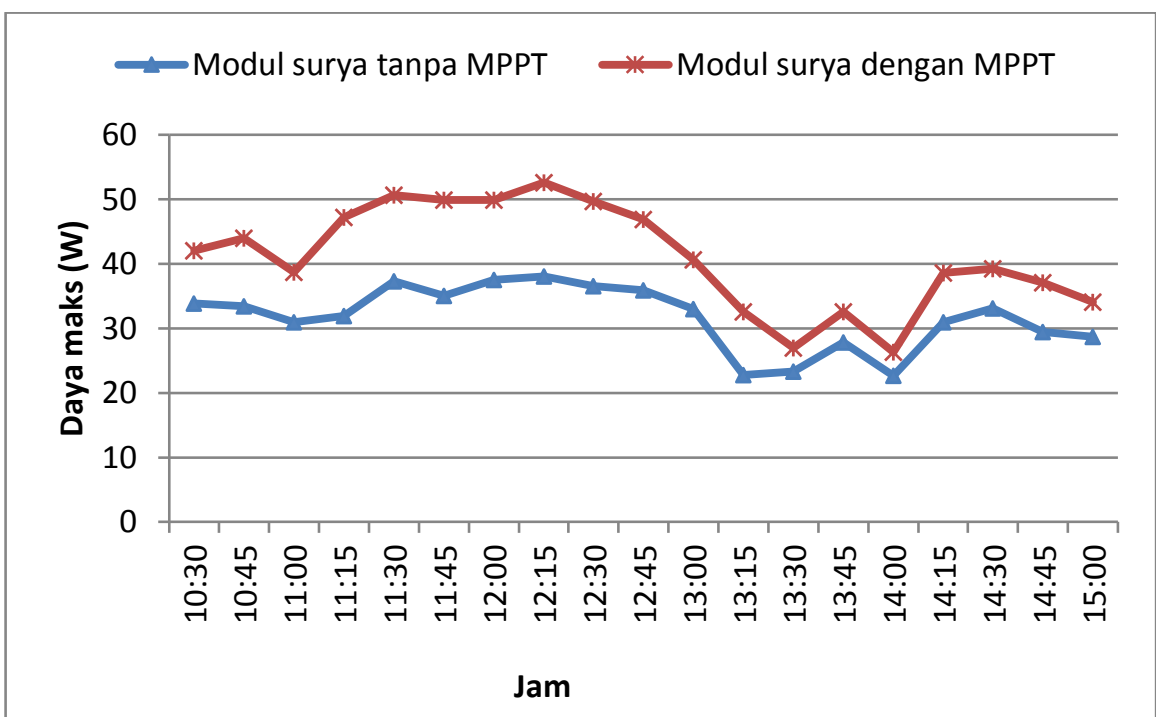

Gambar 6. Grafik perbandingan daya maksimal modul surya dengan MPPT dan tanpa MPPT

Berdasarkan data pada Tabel 1 dan grafik pada Gambar 5 bahwa intensitas radiasi matahari atau Iradiasi memiliki trend kecenderungan maksimum pada siang hari dimulai jam 11.00 - 13.00, meskipun turun sedikit karena pengaruh cuaca. Pada Gambar 6, memperlihatkan grafik perbandingan daya yang dihasilkan modul surya dengan menggunakan MPPT dan tanpa MPPT. Daya yang dihasilkan sistem dengan MPPT lebih besar dibandingkan dengan tanpa MPPT. Pada sistem PLTS daya yang dihasilkan sangat dipengaruhi oleh iradiasi surya, semakin tinggi intensitas surya maka daya yang dihasilkan semakin besar. Sebagai contoh hasil pengukuran terbesar terjadi pada pukul 12.15, menghasilkan daya 52,60 watt untuk sistem dengan MPPT dan daya 38,04 watt untuk sistem tanpa MPPT.

Pelaksanaan kegiatan pengabdian kepada masyarakat melibatkan unsur-unsur yang ada di sekolah yaitu Kepala Sekolah, guru-guru, dan siswa-siswa SMK Negeri 1 Pringgabaya. Kegiatan diawali dengan pertemuan dengan Kepala Sekolah sebagai wujud dari permohonan ijin untuk melakukan presentasi dan demonstrasi kepada siswa-siswi SMKN. Dilanjutkan kegiatan presentasi di kelas yang dihadiri lebih dari 30 orang siswa dan 3 orang guru bidang keahlian teknik listrik dan bidang keahlian elektronika. Kemudian diskusi dan tanya jawab seputar topik PLTS, charger controller, dan MPPT. Serta demonstrasi prototip penerapan penjejak titik daya maksimum pada PLTS skala kecil. 
Aktivitas-aktivitas selama kegiatan pengabdian kepada masyarakat, didokumentasikan dalam foto-foto kegiatan Gambar 7.
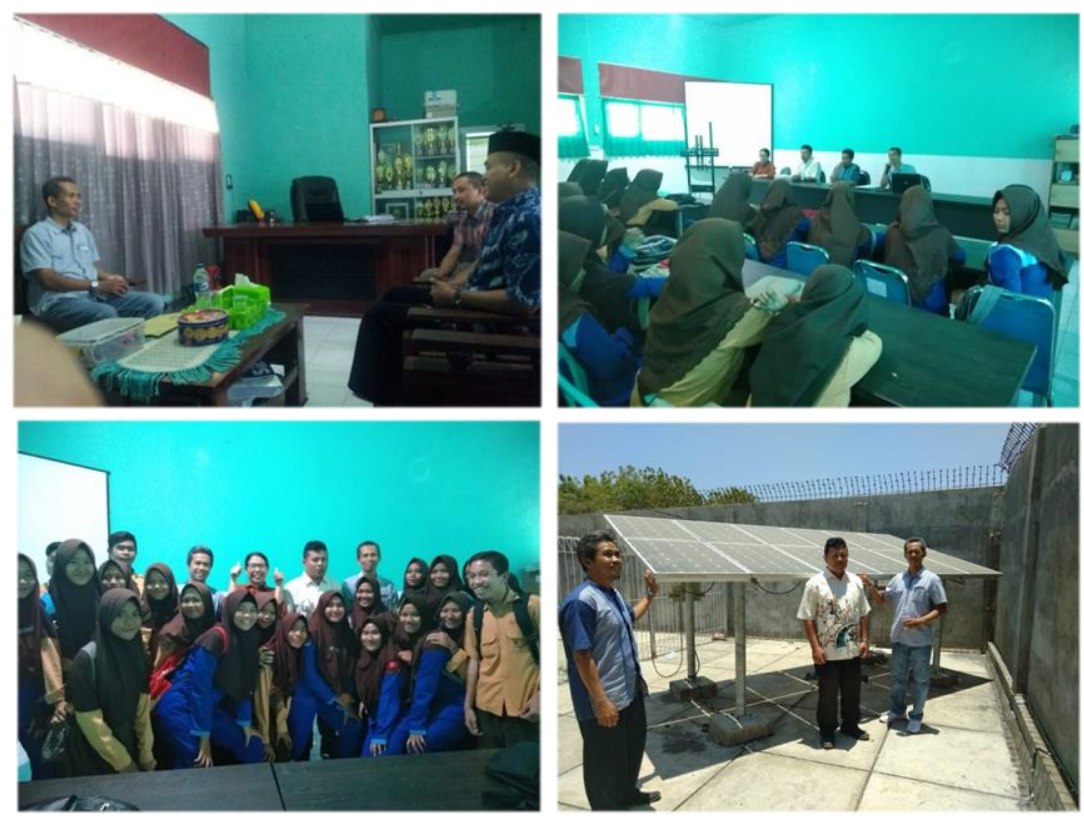

Gambar 7. Dokumentasi kegiatan pengabdian kepada masyarakat

\section{KESIMPULAN DAN SARAN}

Prototip penjejak titik daya maksimum pada solar charger controller yang dirancang, telah diterapkan pada PLTS skala kecil dan mampu memaksimal daya yang dihasilkan modul surya. Data pengukuran menunjukkan bahwa pada pukul 12.15 diperoleh iradiasi maksimum 704,40 Watt/m2, menghasilkan daya maksimum sebesar 52,6 watt dengan menggunakan MPPT dan 38,04 watt tanpa menggunakan MPPT.

Kegiatan pengabdian ini akan meningkatnya motivasi siswa-siswi SMK untuk melakukan inovasi dan kreatifitas terhadap peralatan atau pembangkit energi terbarukan yang ada di sekolah, guna memenuhi kompetensi lulusan yang harus dimiliki.

Saran yang mungkin dilakukan adalah penerapan penjejak titik daya maksimum ini dapat diterapkan untuk PLTS di lokasi lain dan skala yang lebih besar.

\section{UCAPAN TERIMA KASIH}

Penulis mengucapkan terima kasih kepada Universitas Mataram yang telah memberi dukungan dana yang bersumber dari BOPTN tahun 2018 terhadap pengabdian kepada masyarakat ini.

\section{DAFTAR PUSTAKA}

Rekioua, D., and Matagne, E., (2012). Optimization of Photovoltaic Power Systems Modelization, Simulation, and Control, Springer, London, United Kingdom.

Ardana, I. M., Natsir, A., Nrartha, I. M., (2019). Monitoring Daya Output Sistem Fotovoltaik Berbasis Mikrokontoler Atmega328. Dielektrika. vol 6 No. 1 hal 19-29.

Wibawa, M. T. (2015). Penjejakan titik daya maksimum pada sistem fotovoltaik menggunakan boost converter dengan teknik Pertube and Observe, Skripsi. Program Sarjana Teknik Elektro, Universitas Mataram, Mataram. 
Mujahidin, A. (2018). Rancang bangun maximum power point tracking (MPPT) solar charge controller menggunakan metode Perturb and Observe berbasis Arduino uno, Skripsi. Program Sarjana Teknik Elektro, Universitas Mataram, Mataram. 